\title{
Prevalence of overweight and obesity, and associations with socio-demographic factors in Kuwait
}

Victor M. Oguoma ${ }^{1,2,3^{*}}$ (D) Neil T. Coffee ${ }^{1}$, Saad Alsharrah ${ }^{1,2}$, Mohamed Abu-Farha $^{4}$, Faisal H. Al-Refaei ${ }^{4}$, Fahd Al-Mulla ${ }^{4}$ and Mark Daniel ${ }^{1,5}$

\begin{abstract}
Background: Kuwait is amongst countries in the Gulf region with high income economy. According to the World Health Organisation (WHO), one in five adults in the Gulf region is obese. This study sought to evaluate the prevalence and magnitude of association between overweight, obesity, central obesity, and socio-demographic factors in Kuwait.

Methods: A population-based cross-sectional survey of diabetes and obesity in Kuwait - part of the Kuwait Diabetes Epidemiology Program - was conducted between 2011 and 2014, targeting adults aged 18-82 years using the WHO STEPwise approach to non-communicable disease surveillance. Body mass index (BMI) was calculated to classify overweight and obesity, and waist circumference (WC) used to express central obesity. Multivariable logistic regression was used to estimate relationships between socio-demographic factors, overweight $\left(25.0-29.9 \mathrm{~kg} / \mathrm{m}^{2}\right)$, obesity $\left(\geq 30.0 \mathrm{~kg} / \mathrm{m}^{2}\right)$ or central obesity (WC $\geq 80 \mathrm{~cm}$ women; WC $\geq 94 \mathrm{~cm}$ men).

Results: Records for gender (56\% Men), age, BMI, governorate, and nationality existed for 4901 individuals. Mean age and BMI were 43 years and $30 \mathrm{~kg} / \mathrm{m}^{2}$, respectively. Non-Kuwaiti nationals were more prevalent than Kuwaitis (76\% vs 24\%). Prevalence rates for overweight, obesity and central obesity were 40.6\% (95\%Cl: 38.4-42.8\%), 42.1\% (95\% Cl: 40.0-44.3\%) and $73.7 \%$ (95\% Cl: 71.7-75.6\%), respectively. The youngest age group (18-29years) had rates of 38.2\% (95\%Cl: 29.2-47.7\%), 27.2\% (95\%Cl: 19.0-36.7\%) and 49.9\% (95\%Cl: 40.6-59.1\%) for overweight, obesity and central obesity, respectively. In covariate-adjusted analyses, the odds of being overweight was $26 \%$ greater for men than for women. Conversely, women had a 54\% (95\%Cl: 19-99\%) and 7-fold (95\%Cl, 5-10-fold) greater odds of obesity/central obesity, respectively, than men. Greater educational attainment, physical activity, and non-Kuwaiti status were associated with lower odds of obesity/central obesity. History of smoking, elevated blood pressure, higher income, being married, greater age and female sex related to greater odds of obesity/central obesity.

(Continued on next page)
\end{abstract}

\footnotetext{
* Correspondence: victor.oguoma@canberra.edu.au

${ }^{1}$ Australian Geospatial Health Laboratory, Health Research Institute, University

of Canberra, Canberra, Australia

${ }^{2}$ Geohealth Laboratory, Dasman Diabetes Institute, Kuwait City, Kuwait

Full list of author information is available at the end of the article
}

(c) The Author(s). 2021 Open Access This article is licensed under a Creative Commons Attribution 4.0 International License, which permits use, sharing, adaptation, distribution and reproduction in any medium or format, as long as you give appropriate credit to the original author(s) and the source, provide a link to the Creative Commons licence, and indicate if changes were made. The images or other third party material in this article are included in the article's Creative Commons licence, unless indicated otherwise in a credit line to the material. If material is not included in the article's Creative Commons licence and your intended use is not permitted by statutory regulation or exceeds the permitted use, you will need to obtain permission directly from the copyright holder. To view a copy of this licence, visit http://creativecommons.org/licenses/by/4.0/. The Creative Commons Public Domain Dedication waiver (http://creativecommons.org/publicdomain/zero/1.0/) applies to the data made available in this article, unless otherwise stated in a credit line to the data. 
(Continued from previous page)

Conclusion: Overweight was greater in men, obesity greater in women. Overweight and obesity prevalence were high in young adults aged 18-29 years, a significant public health concern. Efforts to integrate mandatory physical education to the school curriculum and promoting the creation of recreation spaces/parks to promote physical activities, will play a vital role in the early prevention of overweight/obesity in Kuwait.

Keywords: Overweight, Obesity, Socio-demographic factors, Kuwait

\section{Background}

Overweight and obesity $(\mathrm{OW} / \mathrm{OB})$ represent excess accumulations of adipose tissue associated with impaired physical as well as psychosocial health and well-being [1, 2]. Across different countries of the world, overweight and obesity are recognised as important public health problems. Decades of evidence show that obese individuals have higher risk of all-cause mortality; a constellation of serious health conditions and diseases such as type 2 diabetes, hypertension, dyslipidaemia, coronary heart disease, stroke, obstructive sleep apnoea, cancers and breathing complications, and difficulty with physical functioning and low quality of life [3-7]. More than 1.9 billion and 650 million adults worldwide aged 18 years and older are overweight and obese, respectively, and the number of deaths attributed to overweight and obesity is greater than that linked to underweight [1].

Kuwait is amongst countries in the Gulf Cooperation Council (GCC) with high income economy. According to the World Health Organisation (WHO), one in five adults in the GCC region is obese. The Global Health Observatory (GHO) data has documented that the agestandardised prevalence rates of overweight and obesity in Kuwait have increased from 51.4 and $18.6 \%$ in 1975 to 73.4 and $37.9 \%$ in 2016 , respectively [8]. A recent cross-sectional study [9] of Kuwait reported for men and women respectively a median body mass index (BMI) of $28 \mathrm{~kg} / \mathrm{m}^{2}$ and $29 \mathrm{~kg} / \mathrm{m}^{2}$, and obesity rates of 36.5 and $44.0 \%$.

A review of the noncommunicable disease profile of Kuwait shows that no operational policy, strategy, or action plan to reduce $\mathrm{OW} / \mathrm{OB}$ and physical inactivity exits at this time $[10,11]$. Further, given few studies addressing $\mathrm{OW} / \mathrm{OB}$ in Kuwait, heterogeneity in how OW/OB have been reported for Kuwait, and an acknowledged international need for ethnic criteria for expressing excess adiposity for unique populations, there is a need to evaluate optimal anthropometric indices for tracking OW/OB in Kuwait [12].

Kuwait is an oil-rich country with significant population of expatriates, and has experienced rapid economic growth and major socio-demographic shifts concomitant with an epidemiological transition in extent of OW/OB over the last seven decades [13]. Non-Kuwaiti's, largely an expatriate population, constitute about $67 \%$ of the population of Kuwait. In 2003, Al-Asi [14] reported that both $\mathrm{OW} / \mathrm{OB}$ and physical inactivity are highly prevalent among expatriates in Kuwait. Kuwaitis, however, are the population segment benefitting most from rapid economic growth. An understanding of the magnitude of $\mathrm{OW} / \mathrm{OB}$ between Kuwaiti and non-Kuwaiti residents is important to inform the development of interventions and obesity control resource allocation.

The WHO defines overweight and obesity as body mass index (BMI) of $25-29.9 \mathrm{~kg} / \mathrm{m}^{2}$ and $\geq 30 \mathrm{~kg} / \mathrm{m}^{2}$, respectively. Promoting a different measure, the International Diabetes Federation (IDF) emphasises excess central (or truncal) obesity using waist circumference (WC) for which the IDF suggests the criterion value, for the Middle East and Mediterranean region, be based on the European threshold, at least until specific data are available for this region [15]. This study sought to contribute data on obesity in the GCC region and to assess the extent of obesity between Kuwaiti and non-Kuwaiti ethnic residents using different anthropometric indices. We also sought to evaluate the prevalence and magnitude of association between overweight, obesity, central obesity, and socio-demographic factors in Kuwait.

\section{Methods}

\section{Study design and participants}

A population-based cross-sectional survey of diabetes and obesity in Kuwait - part of the Kuwait Diabetes Epidemiology Program - was conducted between 2011 to 2014, targeting adults aged 18-82 years. In 2011, the population of Kuwait above 18 years of age (based on the Public Authority of Civil Information (PACI) database) was 2,796,274; comprising of 670,432 Kuwaiti and $2,125,842$ non-Kuwaiti's living in the six governorates. A stratified random sampling technique was used to estimate diabetes prevalence for study participants. Using a computerised register developed by PACI, each of the six Kuwait governorates (Ahmadi, Capital, Farwaniya, Hawally, Jahra, and Mubarak Al Kabeer) was stratified into Kuwaiti and non-Kuwaiti majorities, yielding 12 strata. Within each stratum, a simple random sample of participants was selected to be proportional to the total numbers of the dominant population in each stratum. Stratum-specific sampling assumed a diabetes prevalence of $20 \%$ [16] with a 5\% margin of error and $95 \%$ 
confidence level. Accounting for an anticipated 40\% nonresponse rate, the total adjusted sample size sought was 4917.

\section{Demographics and questionnaire-based variables}

The WHO STEPS questionnaire for non-communicable diseases surveillance was used to collect information on socio-demographic factors, behavioural characteristics (tobacco and alcohol use, diet, level of physical activity, and history of diseases), anthropometric measurements and biochemical parameters for participants [17]. Selfreported socio-demographic and individual characteristics, including gender, age, nationality, ethnicity, average income earnings reported in Kuwaiti Dinah, highest level of education completed, employment status, marital status, smoking history, and physical activity status, were recorded during a face-to-face interview at the Dasman Diabetes Institute. Physical activity questions were derived from the Global Physical Activity Questionnaire [18]. These asked whether participants' work involves moderate-intensity activity and vigorous-intensity activity with small increases in breathing or heart rate such as brisk walking (or carrying light loads) for at least 10 min continuously.

\section{Anthropometric and physical measurements}

Height and weight measured using a human digital column weighing scale with a mounted stadiometer (SECA, Germany), were used to define the BMI [19]. BMI was categorised as underweight $\left(<18.5 \mathrm{~kg} / \mathrm{m}^{2}\right)$, normal weight $\left(18.5-24.9 \mathrm{~kg} / \mathrm{m}^{2}\right)$, overweight $\left(25.0-29.9 \mathrm{~kg} / \mathrm{m}^{2}\right)$ and obese $\left(>30 \mathrm{~kg} / \mathrm{m}^{2}\right)$. The obese category was further subdivided into three classes: Obese class I (35.0-39.9 $\left.\mathrm{kg} / \mathrm{m}^{2}\right)$, Obese class II $\left(35.0-39.9 \mathrm{~kg} / \mathrm{m}^{2}\right)$ and Obese class III $\left(\geq 40.0 \mathrm{~kg} / \mathrm{m}^{2}\right)$ [20].

Central obesity was assessed using waist circumference (WC). WC was measured using a constant tension tape, with arms relaxed at the sides, the highest point of the iliac crest and the mid-axillary line. The WC threshold for Europid ethnicity recommended for individuals from the Middle East and Mediterranean region by the Joint Scientific Statement on Harmonising the Metabolic Syndrome [21] was used. In men, WC $\geq 94 \mathrm{~cm}$ was classified as obesity, in women $W C \geq 80 \mathrm{~cm}$. Additional anthropometric indices, waist-to-hip ratio and wait-to-height ratio, were calculated.

Blood pressure was measured using an Omron HEM907XL digital sphygmomanometer (Omron Healthcare, Inc., Vernon Hills, IL, USA). Average of three readings of systolic and diastolic blood pressure was used to define an individual's systolic and diastolic blood pressure readings. Elevated blood pressure was defined for both the American College of Cardiology/American Heart Association Hypertension (ACC/AHA) guideline (early high blood pressure $=130 / 80 \mathrm{mmHg}$ ] [22]) and the World Health Organisation (WHO) cut point (140/90 $\mathrm{mmHg}$ [12]).

\section{Statistical analysis}

Sampling weight was calculated by dividing the stratumspecific total sample population in the year 2011 by the estimated sample size for each stratum, based on the proportional allocation sampling approach. Statistical analysis was conducted using Stata 16.1 (StataCorp, College Station, TX, USA) using the survey estimation command. Descriptive statistics were calculated, stratified by age group and gender. Normally distributed continuous variables are presented as mean and standard deviation or standard error; categorical variables are presented as counts and percentages.

The Taylor-linearized variance estimation and Clopper-Pearson exact 95\% confidence interval (CI) were used to derive prevalence estimates for overweight, obesity and central obesity. Straightforward categories of overweight $\left(25-29.9 \mathrm{~kg} / \mathrm{m}^{2}\right)$ or obese $\left(\geq 30 \mathrm{~kg} / \mathrm{m}^{2}\right)$ were created. Logistic regression was used to assess predictors of overweight, obesity and central obesity. Univariate logistic regression was conducted to identify sociodemographic factors and behaviours associated with overweight or obesity. Factors having a statistical significance of $p<0.25$ were used in fitting a multivariable logistic regression solution using overweight, obesity, or central obesity as separate outcomes. Each of the predictors that constitute the fully adjusted model were included in a sequential order and model performance assessed using the Akaike Information criterion (AIC). Only the fully adjusted models were reported. No multiple imputation of missing data was performed; only the observed data were analysed. Statistical significance was set at $p<0.05$. A choropleth map of the prevalence of overweight, obesity/central obesity was created using QGIS version 3.12.1 - a free and open-source software.

\section{Results}

\section{Baseline characteristics of study population}

The sample size surveyed was 5291 . Table 1 presents sample characteristics stratified by gender. Four thousand nine hundred one (92.6\%) individuals had valid records of which $57 \%$ were men, and $43 \%$ women. The weighted mean age of participants was 43 years. The population comprised predominantly middle-aged individuals with the highest proportion (37\%) aged 40-49 years. The weighted percentages for the youngest (1929 years) and oldest categories ( $>60$ years) were 9 and $6 \%$, respectively. There were more non-Kuwaiti than Kuwaiti (weighted: $76 \%$ vs $24 \%$ ) in the study population. Forty-eight percent (weighted) of the population had completed a bachelor's degree, $51 \%$ are women. The 
Table 1 Study characteristics by gender

\begin{tabular}{|c|c|c|c|c|c|c|}
\hline \multirow[t]{4}{*}{ Characteristics } & \multicolumn{3}{|c|}{ Unweighted } & \multicolumn{3}{|l|}{ Weighted } \\
\hline & Male & Female & Total & Male & Female & Total \\
\hline & $N=2750$ & $N=2151$ & $N=4901$ & $N=1,694,841$ & $N=1,101,433$ & $N=2,796,274$ \\
\hline & n (\%) & n (\%) & n (\%) & n (\%) & n (\%) & n (\%) \\
\hline Age (years) mean (SD or SE) & $44.6(10.4)$ & $43.3(10.3)$ & $44.0(10.4)$ & $43.2(0.3)$ & $42.0(0.3)$ & $42.7(0.2)$ \\
\hline \multicolumn{7}{|l|}{ Age group } \\
\hline $18-29$ & $191(6.9)$ & $181(8.4)$ & $372(7.6)$ & $152,751(9.0)$ & $101,688(9.2)$ & $254,440(9.1)$ \\
\hline $30-39$ & $688(25.0)$ & $618(28.7)$ & $1306(26.6)$ & $455,229(26.9)$ & $362,855(32.9)$ & $818,084(29.3)$ \\
\hline $40-49$ & $1010(36.7)$ & $798(37.1)$ & $1808(36.9)$ & $639,939(37.8)$ & $392,937(35.7)$ & $1,032,876(36.9)$ \\
\hline $50-59$ & $642(23.3)$ & $385(17.9)$ & $1027(21.0)$ & $345,495(20.4)$ & $182,359(16.6)$ & $527,854(18.9)$ \\
\hline$\geq 60$ & $219(8.0)$ & $169(7.9)$ & $388(7.9)$ & $101,426(6.0)$ & $61,594(5.6)$ & $163,020(5.8)$ \\
\hline \multicolumn{7}{|l|}{ Nationality } \\
\hline Kuwaiti & $867(31.5)$ & $822(38.2)$ & $1689(34.5)$ & $340,897(20.1)$ & 329,535 (29.9) & $670,432(24.0)$ \\
\hline non-Kuwaiti, specify & $1883(68.5)$ & $1329(61.8)$ & $3212(65.5)$ & $1,353,945(79.9)$ & $771,897(70.1)$ & $2,125,842(76.0)$ \\
\hline \multicolumn{7}{|l|}{ Ethnicity } \\
\hline Arab & $1741(63.6)$ & $1492(69.5)$ & $3233(66.2)$ & $932,282(55.2)$ & $689,155(62.7)$ & $1,621,436(58.2)$ \\
\hline Iranian & $100(3.7)$ & $68(3.2)$ & $168(3.4)$ & $74,380(4.4)$ & $43,603(4.0)$ & $117,983(4.2)$ \\
\hline South Asian & $744(27.2)$ & $303(14.1)$ & $1047(21.4)$ & $560,374(33.2)$ & $164,237(14.9)$ & $724,611(26.0)$ \\
\hline Southeast Asia & $139(5.1)$ & $268(12.5)$ & $407(8.3)$ & $107,873(6.4)$ & $193,709(17.6)$ & $301,582(10.8)$ \\
\hline Other & $15(0.5)$ & $15(0.7)$ & $30(0.6)$ & $13,497(0.8)$ & $8969(0.8)$ & $22,466(0.8)$ \\
\hline \multicolumn{7}{|l|}{ Average Income } \\
\hline$\leq 500$ & $826(35.5)$ & $517(31.4)$ & $1343(33.8)$ & $668,554(47.3)$ & $302,892(37.5)$ & $971,446(43.7)$ \\
\hline$>500-1500$ & $784(33.7)$ & $532(32.3)$ & $1316(33.1)$ & $442,577(31.3)$ & $266,998(33.1)$ & 709,575 (31.9) \\
\hline$>1500$ & $716(30.8)$ & $598(36.3)$ & $1314(33.1)$ & $303,009(21.4)$ & $237,961(29.5)$ & $540,970(24.3)$ \\
\hline \multicolumn{7}{|l|}{ Education } \\
\hline Illiterate & $17(0.6)$ & $40(1.9)$ & $57(1.2)$ & $8148(0.5)$ & $40,831(3.7)$ & $48,980(1.8)$ \\
\hline Read and write & $469(17.1)$ & $360(16.8)$ & $829(17.0)$ & $323,163(19.1)$ & $206,017(18.7)$ & $529,181(19.0)$ \\
\hline Secondary School & $711(25.9)$ & $487(22.7)$ & $1198(24.5)$ & $448,744(26.6)$ & $250,252(22.7)$ & $698,996(25.1)$ \\
\hline University & 1305 (47.6) & $1157(53.9)$ & $2462(50.3)$ & $774,114(45.8)$ & $556,085(50.5)$ & $1,330,199(47.7)$ \\
\hline High studies & $240(8.8)$ & $104(4.8)$ & $344(7.0)$ & $135,937(8.0)$ & $47,008(4.3)$ & $182,945(6.6)$ \\
\hline \multicolumn{7}{|l|}{ Occupation } \\
\hline Employed & $2416(88.5)$ & $1219(56.8)$ & $3635(74.5)$ & $1,547,480(92.1)$ & $627,081(57.0)$ & $2,174,562(78.2)$ \\
\hline Student, not employed & $16(0.6)$ & $24(1.1)$ & $40(0.8)$ & $9368(0.6)$ & $15,264(1.4)$ & $24,632(0.9)$ \\
\hline Housewife, not employed & $0(0.0)$ & $619(28.8)$ & $619(12.7)$ & $0(0.0)$ & $359,074(32.7)$ & $359,074(12.9)$ \\
\hline Retired & $282(10.3)$ & $211(9.8)$ & $493(10.1)$ & $102,231(6.1)$ & $72,732(6.6)$ & $174,963(6.3)$ \\
\hline Unemployed & $16(0.6)$ & $73(3.4)$ & $89(1.8)$ & $20,777(1.2)$ & $25,168(2.3)$ & $45,944(1.7)$ \\
\hline \multicolumn{7}{|l|}{ Marital status } \\
\hline Never married & $208(7.6)$ & $180(8.4)$ & $388(7.9)$ & $153,251(9.0)$ & $104,773(9.5)$ & $258,024(9.2)$ \\
\hline currently married & $2497(90.8)$ & $1788(83.2)$ & $4285(87.4)$ & $1,524,389(89.9)$ & $920,290(83.6)$ & $2,444,679(87.4)$ \\
\hline Divorced & $35(1.3)$ & $104(4.8)$ & $139(2.8)$ & $13,535(0.8)$ & $46,328(4.2)$ & $59,864(2.1)$ \\
\hline Widowed & $10(0.4)$ & $78(3.6)$ & $88(1.8)$ & $3666(0.2)$ & $29,782(2.7)$ & $33,448(1.2)$ \\
\hline \multicolumn{7}{|l|}{ Current smoker } \\
\hline No & $1813(66.1)$ & 1916 (89.3) & $3729(76.3)$ & $1,171,971(69.3)$ & $1,003,578(91.3)$ & $2,175,549(78.0)$ \\
\hline Yes & $930(33.9)$ & $230(10.7)$ & 1160 (23.7) & $518,974(30.7)$ & $96,096(8.7)$ & $615,070(22.0)$ \\
\hline
\end{tabular}


Table 1 Study characteristics by gender (Continued)

\begin{tabular}{|c|c|c|c|c|c|c|}
\hline \multirow[t]{2}{*}{ Characteristics } & \multicolumn{3}{|c|}{ Unweighted } & \multicolumn{3}{|l|}{ Weighted } \\
\hline & $\begin{array}{l}\text { Male } \\
N=2750 \\
\mathrm{n}(\%)\end{array}$ & $\begin{array}{l}\text { Female } \\
N=2151 \\
\mathrm{n}(\%)\end{array}$ & $\begin{array}{l}\text { Total } \\
N=4901 \\
\text { n (\%) }\end{array}$ & $\begin{array}{l}\text { Male } \\
N=1,694,841 \\
\text { n (\%) }\end{array}$ & $\begin{array}{l}\text { Female } \\
N=1,101,433 \\
\text { n (\%) }\end{array}$ & $\begin{array}{l}\text { Total } \\
N=2,796,274 \\
\text { n (\%) }\end{array}$ \\
\hline \multicolumn{7}{|l|}{ Past smoker } \\
\hline No & $1319(71.5)$ & $1844(97.1)$ & $3163(84.4)$ & $829,021(70.0)$ & $965,412(97.0)$ & $1,794,433(82.3)$ \\
\hline Yes & $527(28.5)$ & $56(2.9)$ & $583(15.6)$ & $355,031(30.0)$ & $29,984(3.0)$ & $385,015(17.7)$ \\
\hline \multicolumn{7}{|l|}{ Vigorous-intensity physical activity } \\
\hline No & $2681(97.8)$ & $2114(98.4)$ & $4795(98.1)$ & $1,649,847(97.6)$ & $1,072,917(97.5)$ & $2,722,764(97.6)$ \\
\hline Yes & $61(2.2)$ & $34(1.6)$ & $95(1.9)$ & $40,838(2.4)$ & $27,275(2.5)$ & $68,114(2.4)$ \\
\hline \multicolumn{7}{|l|}{ Moderate-intensity physical activity } \\
\hline No & $2505(91.5)$ & $1984(92.4)$ & 4489 (91.9) & $1,505,793(89.2)$ & $1,017,283(92.5)$ & $2,523,076(90.5)$ \\
\hline Yes & $233(8.5)$ & $163(7.6)$ & $396(8.1)$ & $181,541(10.8)$ & $82,650(7.5)$ & $264,191(9.5)$ \\
\hline \multicolumn{7}{|l|}{ Elevated blood pressure (ACC/AHA) } \\
\hline No & $1596(58.2)$ & $1637(76.3)$ & $3233(66.2)$ & $947,366(56.0)$ & $819,426(74.5)$ & $1,766,792(63.3)$ \\
\hline Yes & $1145(41.8)$ & $509(23.7)$ & $1654(33.8)$ & $743,060(44.0)$ & $280,248(25.5)$ & $1,023,307(36.7)$ \\
\hline \multicolumn{7}{|l|}{ Elevated blood pressure (WHO) } \\
\hline No & $2348(85.7)$ & $1960(91.3)$ & $4308(88.2)$ & $1,421,989(84.1)$ & $997,897(90.7)$ & $2,419,886(86.7)$ \\
\hline Yes & $393(14.3)$ & $186(8.7)$ & $579(11.8)$ & $268,437(15.9)$ & $101,776(9.3)$ & $370,213(13.3)$ \\
\hline Height (m); mean (SD or SE) & $1.7(0.1)$ & $1.6(0.1)$ & $1.7(0.1)$ & $1.7(0.0)$ & $1.6(0.0)$ & $1.7(0.0)$ \\
\hline Weight (kg); mean (SD or SE) & $86.5(17.5)$ & $76.8(17.1)$ & $82.3(18.0)$ & $85.8(0.6)$ & $75.9(0.5)$ & $81.9(0.4)$ \\
\hline Waist Circumference (cm); mean (SD or SE) & $99.5(13.2)$ & $95.3(13.5)$ & $97.7(13.5)$ & $99.1(0.4)$ & $95.3(0.4)$ & $97.6(0.3)$ \\
\hline Hip Circumference (cm); mean (SD or SE) & $105.5(10.7)$ & $108.5(12.8)$ & $106.9(11.8)$ & $104.9(0.3)$ & $107.6(0.3)$ & $105.9(0.2)$ \\
\hline Waist to height ratio; mean (SD or SE) & $0.6(0.1)$ & $0.6(0.1)$ & $0.6(0.1)$ & $0.6(0.0)$ & $0.6(0.0)$ & $0.6(0.0)$ \\
\hline
\end{tabular}

average weighted weight and waist circumference were $82 \mathrm{~kg}$ and $98 \mathrm{~cm}$, respectively, higher in men compared to women.

Table S1 indicates a higher weighted proportion 55\% of participants aged 18-29 years old earning less than five hundred Kuwaiti Dinah compared to older adults in other age groupings. Across age groups, university education outweighed other levels of education.

Table S2 indicates that the proportion of non-Kuwaiti with average monthly household income $\leq$ KD1500 was higher compared to Kuwaiti, while Kuwaiti were most represented (weighted: $77 \%$ ) in the high-income group (>KD1500). Across nationalities, most participants had a bachelor's degree. In both unweighted and weighted descriptive analysis, more Kuwaiti than non-Kuwaiti had completed a university education (63\% versus $44 \%$, respectively).

Prevalence of overweight, obesity and central obesity

Figure 1 Weighted prevalence rates of overweight and obesity were, overall, 40.6\% (95\%CI: 38.4-42.8\%) and 42.1\% (95\%CI: 40.0-44.3\%), respectively. Obesity rates for obesity classes I, II and III were $26.1 \%$ (95\%CI: $24.2-$ 28.1\%), $10.3 \%$ (95\%CI: $9.0-11.6 \%$ ), and 5.7\% (95\%CI:
4.5-6.9\%), respectively. The prevalence of central obesity was $73.7 \%$ (95\%CI: 71.7-75.6\%). Men were more overweight $43.5 \%$ (95\%: 40.6-46.4\%) than women $35.9 \%$ (95\%: 32.8-39.1\%). Obesity and central obesity were greater in women (47.9 and $90.5 \%)$ relative to men $(38.5$ and $62.9 \%$ ), respectively. Non-Kuwaiti's were more overweight $41.9 \%$ (95\%CI: 39.2-44.7\%) than Kuwaiti's 36.2\% (95\%CI: 33.7-38.7\%). Obesity and central obesity were greater in Kuwaiti's relative to non-Kuwaiti's. Across age groups, overweight rose slightly from 19 to 29 years, plateaued between ages 30 to 59 and then declined at age $>60$ years (Fig. 2). Obesity and central obesity both rose with increasing age.

Figure 3 shows the choropleth map of the prevalence of overweight, obesity and central obesity according to governorate. Ahmadi 47.6\% (95\%CI: 41.7-52.3) had the highest prevalence of overweight, while Jahra had the highest prevalence of obesity and central obesity.

\section{Association of overweight, obesity and central obesity with socio-demographic factors}

Table 2 provides univariate and multivariable analysis results for overweight. In adjusted analysis, women had lower odds of overweight $[\mathrm{AOR}=0.79$ (95\%CI: 0.64- 


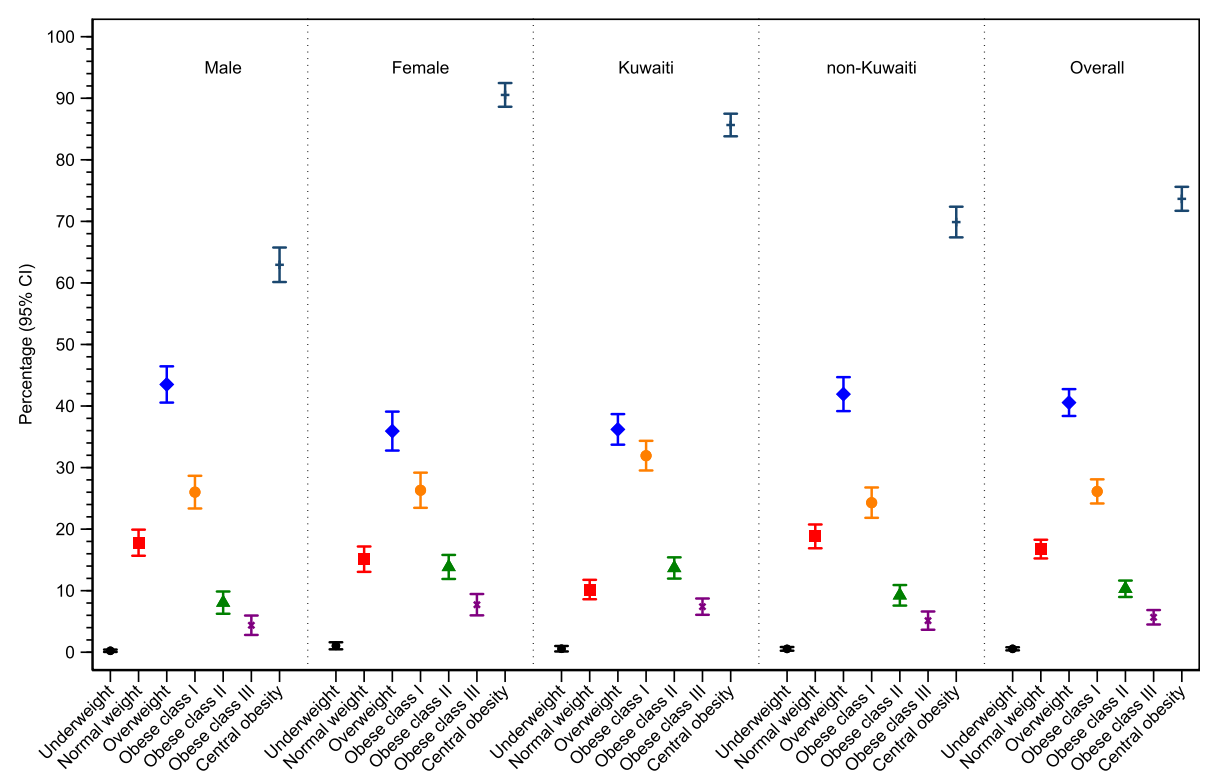

Fig. 1 Prevalence of overweight and obesity stratified by gender, nationality, and overall

0.99); $p=0.04$ ] compared to men. In univariate analysis, non-Kuwaiti had a $27 \%$ greater odds of overweight compared to Kuwaitis; this difference was attenuated, however, after accounting for sociodemographic factors. Individuals with average monthly household income $>1500$ were less likely to be overweight compared to those who earn $\leq 500$.

Table 3 shows both univariate and adjusted analyses of obesity and central obesity. In the adjusted analysis, women had 54\% (95\%CI: 19-99\%) and 7-fold (95\%CI:
5.2 to 10.5 -fold) greater odds of obesity and central obesity, respectively, compared to men, a substantial gender difference. The odds of obesity and central obesity also rose with advancing age. Respondents $>60$ years had a $79 \%$ and 3.1 -fold greater odds of obesity and central obesity, respectively, compared to the youngest age group (18-29 years) after accounting for sociodemographic factors. Non-Kuwaiti's had a lower odd of obesity than Kuwaiti counterparts, but the difference was attenuated with adjustment for socio-demographic

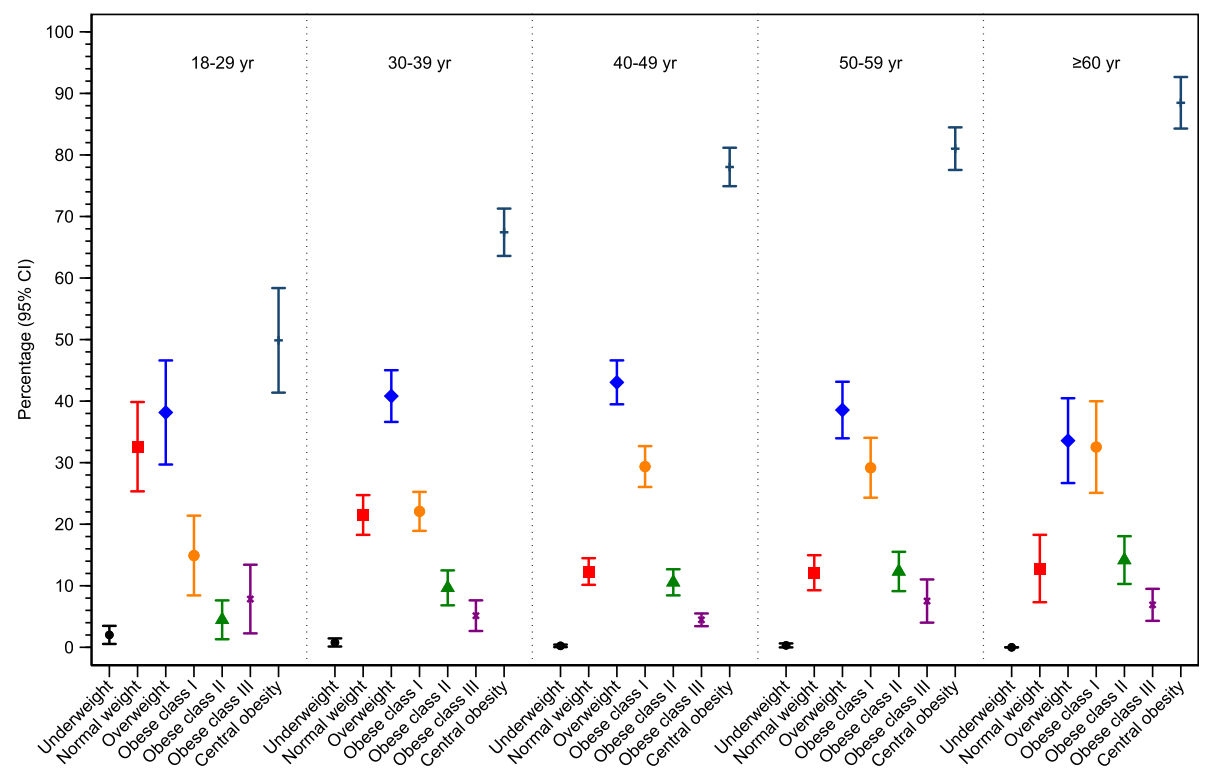

Fig. 2 Prevalence of overweight and obesity stratified by age group 

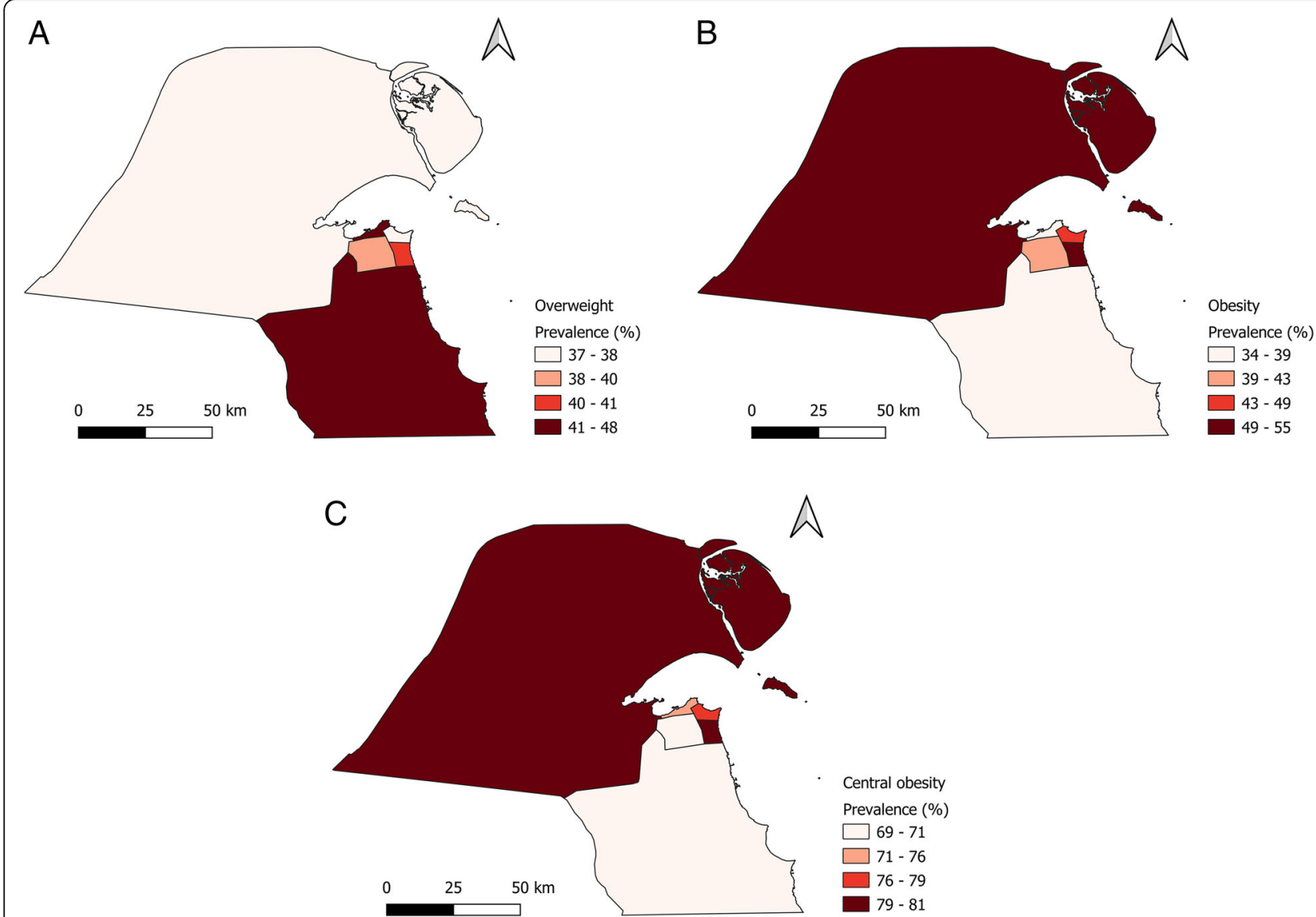

Fig. 3 Prevalence of overweight and obesity by governorate. Map of the prevalence of overweight and obesity by governorate was created using free open-source QGIS software version 3.12.1

factors. Status as non-employed housewife was associated with a greater odd of being obese. Higher average income, previous history of smoking, and elevated blood pressure, were all associated with higher odds of obesity.

\section{Relative odds of overweight, obesity and central obesity by age group and gender}

Figure 4 shows the relative odds of overweight, obesity and central obesity. The gender difference in the trend of overweight and obesity across age groups was retained even after adjustment for socio-demographic factors. The relative odds of overweight was higher for men than for women, and for obesity higher for women than for men. For central obesity, there was a steep rise with increasing age in the relative odds of central obesity in women. In men, increases in central obesity across increasing age groups was little after accounting for other socio-demographic factors.

\section{Discussion}

This representative study of predominant Kuwaiti and non-Kuwaiti population groups indicates a high prevalence of overweight, obesity and central obesity in Kuwait. Some $83 \%$ of participants were overweight or obese, and $74 \%$ had central obesity. This prevalence reveals a large national burden of overweight/obesity and central obesity in Kuwait. Men were more overweight than women, while women were more obese than men. Non-Kuwaiti were more overweight than Kuwaiti, while Kuwaiti were more obese than non-Kuwaiti. This finding is consistent with a recent report specifically for Kuwait [9] as well as earlier reports in other countries in the GCC, including Qatar [23], Saudi Arabia [24, 25], United Arab Emirates [26] and Bahrain [27]. Earlier cultural practices whereby women were discouraged from engaging in voluntary exercise, and valued for plumpness may, in combination with increasing consumption of calorie dense western foods, be a contributing factor to higher prevalence of obesity in women compared to men [28-30].

The trend to greater levels of overweight and obesity with advancing age has been studied extensively [31-33] and is evident also in our results. It is known that the population dynamics in many high-income countries 
Table 2 Univariate and Multivariable analysis of association of overweight and study characteristics

\begin{tabular}{|c|c|c|c|c|}
\hline & Univariate & $p$-value & Multivariable $^{a}$ & $p$-value \\
\hline & \multicolumn{2}{|l|}{ OR $(95 \% \mathrm{Cl})$} & \multicolumn{2}{|l|}{ OR $(95 \% \mathrm{CI})$} \\
\hline \multicolumn{5}{|l|}{ Gender } \\
\hline Male & $1.00(1.00,1.00)$ & . & $1.00(1.00,1.00)$ & . \\
\hline Female & $0.72(0.60,0.86)$ & $<0.001$ & $0.79(0.64,0.99)$ & 0.04 \\
\hline \multicolumn{5}{|l|}{ Age group } \\
\hline $18-29$ & $1.00(1.00,1.00)$ & . & $1.00(1.00,1.00)$ & \\
\hline $30-39$ & $1.15(0.77,1.70)$ & 0.50 & $1.16(0.75,1.78)$ & 0.50 \\
\hline $40-49$ & $1.26(0.86,1.86)$ & 0.23 & $1.37(0.89,2.11)$ & 0.15 \\
\hline $50-59$ & $1.06(0.71,1.59)$ & 0.77 & $1.23(0.78,1.96)$ & 0.37 \\
\hline$\geq 60$ & $0.84(0.53,1.35)$ & 0.48 & $0.88(0.50,1.54)$ & 0.66 \\
\hline \multicolumn{5}{|l|}{ Nationality } \\
\hline Kuwaiti & $1.00(1.00,1.00)$ & . & $1.00(1.00,1.00)$ & . \\
\hline non-Kuwaiti, specify & $1.27(1.09,1.48)$ & $<0.001$ & $1.07(0.80,1.42)$ & 0.65 \\
\hline \multicolumn{5}{|l|}{ Education } \\
\hline Illiterate & $1.00(1.00,1.00)$ & . & $1.00(1.00,1.00)$ & \\
\hline Read and write & $5.17(1.79,14.99)$ & $<0.001$ & $2.11(0.81,5.54)$ & 0.13 \\
\hline Secondary School & $4.98(1.73,14.30)$ & $<0.001$ & $1.81(0.69,4.74)$ & 0.22 \\
\hline University & $5.13(1.81,14.58)$ & $<0.001$ & $2.14(0.82,5.55)$ & 0.12 \\
\hline High studies & $6.82(2.31,20.14)$ & $<0.001$ & $2.43(0.88,6.68)$ & 0.09 \\
\hline \multicolumn{5}{|l|}{ Occupation } \\
\hline Employed & $1.00(1.00,1.00)$ & & $1.00(1.00,1.00)$ & . \\
\hline Student, not employed & $1.26(0.35,4.47)$ & 0.72 & $2.35(0.49,11.15)$ & 0.28 \\
\hline Housewife, not employed & $0.65(0.48,0.88)$ & 0.01 & $0.75(0.51,1.10)$ & 0.14 \\
\hline Retired & $0.76(0.61,0.95)$ & 0.02 & $1.03(0.77,1.38)$ & 0.85 \\
\hline Unemployed & $0.27(0.13,0.54)$ & $<0.001$ & $0.82(0.36,1.87)$ & 0.63 \\
\hline \multicolumn{5}{|l|}{ Marital status } \\
\hline Never married & $1.00(1.00,1.00)$ & . & - & - \\
\hline currently married & $1.17(0.82,1.67)$ & 0.40 & - & - \\
\hline Divorced & $0.95(0.53,1.70)$ & 0.86 & - & - \\
\hline Widowed & $0.94(0.48,1.85)$ & 0.86 & - & - \\
\hline \multicolumn{5}{|l|}{ Average Income } \\
\hline$\leq 500$ & $1.00(1.00,1.00)$ & . & $1.00(1.00,1.00)$ & . \\
\hline$>500-1500$ & $0.87(0.69,1.11)$ & 0.26 & $0.89(0.68,1.15)$ & 0.37 \\
\hline$>1500$ & $0.75(0.61,0.93)$ & 0.01 & $0.80(0.56,1.13)$ & 0.21 \\
\hline \multicolumn{5}{|l|}{ Current smoker } \\
\hline No & $1.00(1.00,1.00)$ & . & $1.00(1.00,1.00)$ & . \\
\hline Yes & $1.15(0.93,1.42)$ & 0.19 & $1.06(0.84,1.35)$ & 0.60 \\
\hline \multicolumn{5}{|l|}{ Past smoker } \\
\hline No & $1.00(1.00,1.00)$ & . & - & - \\
\hline Yes & $0.91(0.67,1.24)$ & 0.55 & - & - \\
\hline \multicolumn{5}{|c|}{ Vigorous-intensity physical activity } \\
\hline No & $1.00(1.00,1.00)$ & . & - & - \\
\hline Yes & $1.03(0.56,1.90)$ & 0.93 & - & - \\
\hline
\end{tabular}


Table 2 Univariate and Multivariable analysis of association of overweight and study characteristics (Continued)

\begin{tabular}{|c|c|c|c|c|}
\hline & Univariate & $p$-value & Multivariable $^{a}$ & $p$-value \\
\hline & \multicolumn{2}{|l|}{ OR $(95 \% \mathrm{Cl})$} & \multicolumn{2}{|l|}{ OR $(95 \% \mathrm{Cl})$} \\
\hline \multicolumn{5}{|c|}{ Moderate-intensity physical activity } \\
\hline No & $1.00(1.00,1.00)$ & & - & - \\
\hline Yes & $0.83(0.57,1.20)$ & 0.32 & - & - \\
\hline \multicolumn{5}{|c|}{ Elevated blood pressure (ACC/AHA) } \\
\hline No & $1.00(1.00,1.00)$ & & - & - \\
\hline Yes & $1.11(0.91,1.34)$ & 0.30 & - & - \\
\hline \multicolumn{5}{|c|}{ Elevated blood pressure (WHO) } \\
\hline No & $1.00(1.00,1.00)$ & & - & - \\
\hline Yes & $0.93(0.70,1.24)$ & 0.62 & - & - \\
\hline
\end{tabular}

${ }^{a}$ Adjusted for gender, age group, nationality, education, occupation, average monthly household income and current smoking status

have seen many of these countries witnessing high increase in life expectancy. However, the increase in life expectancy is often accompanied with additional years of susceptibility to various chronic conditions associated with overweight and obesity in later life [34]. This trend heralds a major burden posed to the healthcare system in managing a large elderly population with multiple comorbidities. Therefore, appropriate public health preventive measures to reduce overweight, obesity and or comorbidities in later life will aid in reducing healthcare costs. This is of relevance given that about 38 and $27 \%$ of study population within the age group of 18-29 years are already overweight and obese, respectively, with $50 \%$ having central obesity, and the likelihood that these rates will rise with age.

Socio-economic status is well known to influence risk factors for cardiovascular disease including overweight and obesity. The extent to which overweight/obesity associate with socio-economic indices depends on the economic development of the country [35-39]. Evidence in developed western countries suggests an inverse relationship between socio-economic indices and overweight/obesity among the adult population [40-43]. However, in developing countries, and in other highincome countries experiencing an epidemiological transition of obesity, the relationship has been inconsistent for many years [44]. An earlier report from China found that lower educational level and higher income were risk factors for obesity [45], while another found no evidence in the relationship [38]. Our study found that individuals within the higher income group were less likely to be overweight. This could be explained by the notion that as countries develop economically with rising prevalence of overweight, a larger proportion of overweight populations becomes relatively poor [46]. This association was the opposite for obesity, whereby the higher income group were more likely to be obese than the lower income group. This is because $78 \%$ (weighted) of participants were employed with a significant proportion earning above 500 Kuwaiti Dinah monthly per household (Table S1) - many of whom are expatriates or locals in high income employments. Several possible drivers of this patterning between overweight and obesity is attributed to a strong culture of physical inactivity and smoking [47], and beliefs that view individuals with obese physique as appealing and sign of affluence [48]. Also, the unemployed were less likely to be overweight and obese compared to those employed, after accounting for other factors.

Twenty-two percent and $18 \%$ of the sampled population were current and past smokers, respectively, and for each smoking history, men were more represented than women. An earlier study in Kuwait and Bahrain reported similar prevalence rates for smoking and differences across gender, although considerably higher for Kuwait than Bahrain [49]. Gender-specific prevalence rates in our study are lower, however, than those reported by RR Hamadeh [50] for the GCC countries in the 90s. Our results from adjusted analyses found that a history of smoking was directly associated with higher odds of obesity defined by BMI and central obesity. For current smokers, a stronger association with smoking was found for central obesity than for obesity defined per BMI. Our findings are consistent with a study from UK general population of 499,504 adults, which found that smoking was strongly associated with higher risk of obesity [51].

Estimates of physical activity were low. Weighted moderate and vigorous physical inactivity levels were 91 and $98 \%$. This suggests that nearly all participants were physically inactive, in concordance with the report of the WHO that indicates that Kuwait, in conjunction with Iraq and Saudi Arabia were among the countries in the world with the highest prevalence of physical inactivity [52]. Our study further found that 
Table 3 Univariate and Multivariable analysis of association of obesity, Central Obesity, and study characteristics

\begin{tabular}{|c|c|c|c|c|c|c|c|c|}
\hline \multirow[t]{3}{*}{ Characteristics } & \multicolumn{4}{|l|}{ Obesity } & \multicolumn{4}{|l|}{ Central Obesity } \\
\hline & \multicolumn{2}{|l|}{ Univariate } & \multicolumn{2}{|l|}{ Multivariable $^{a}$} & \multicolumn{2}{|l|}{ Univariate } & \multicolumn{2}{|l|}{ Multivariable $^{\mathbf{b}}$} \\
\hline & OR (95\% Cl) & $p$-value & OR $(95 \% \mathrm{Cl})$ & $p$-value & OR $(95 \% \mathrm{Cl})$ & $p$-value & OR (95\% CI) & $p$-value \\
\hline \multicolumn{9}{|l|}{ Gender } \\
\hline Male & $1.00(1.00,1.00)$ & . & $1.00(1.00,1.00)$ & . & $1.00(1.00,1.00)$ & . & $1.00(1.00,1.00)$ & . \\
\hline Female & $1.49(1.24,1.78)$ & $<0.001$ & $1.54(1.19,1.99)$ & $<0.001$ & $5.64(4.37,7.27)$ & $<0.001$ & $7.39(5.21,10.49)$ & $<0.001$ \\
\hline \multicolumn{9}{|l|}{ Age group } \\
\hline $18-29$ & $1.00(1.00,1.00)$ & & $1.00(1.00,1.00)$ & & $1.00(1.00,1.00)$ & & $1.00(1.00,1.00)$ & \\
\hline $30-39$ & $1.42(0.91,2.21)$ & 0.12 & $1.29(0.75,2.21)$ & 0.36 & $2.08(1.42,3.06)$ & $<0.001$ & $0.95(0.48,1.86)$ & 0.88 \\
\hline $40-49$ & $1.93(1.25,2.97)$ & $<0.001$ & $1.63(0.95,2.82)$ & 0.08 & $3.57(2.43,5.25)$ & $<0.001$ & $1.86(0.92,3.75)$ & 0.08 \\
\hline $50-59$ & $2.30(1.46,3.64)$ & $<0.001$ & $1.49(0.83,2.68)$ & 0.18 & $4.29(2.85,6.46)$ & $<0.001$ & $1.92(0.91,4.06)$ & 0.09 \\
\hline$\geq 60$ & $2.76(1.67,4.56)$ & $<0.001$ & $1.79(0.90,3.55)$ & 0.10 & $7.71(4.53,13.15)$ & $<0.001$ & $3.10(1.24,7.76)$ & 0.02 \\
\hline \multicolumn{9}{|l|}{ Nationality } \\
\hline Kuwaiti & $1.00(1.00,1.00)$ & . & $1.00(1.00,1.00)$ & . & $1.00(1.00,1.00)$ & . & $1.00(1.00,1.00)$ & . \\
\hline non-Kuwaiti, specify & $0.56(0.48,0.66)$ & $<0.001$ & $0.75(0.54,1.05)$ & 0.10 & $0.39(0.32,0.47)$ & $<0.001$ & $0.58(0.38,0.87)$ & 0.01 \\
\hline \multicolumn{9}{|l|}{ Education } \\
\hline Illiterate & $1.00(1.00,1.00)$ & . & $1.00(1.00,1.00)$ & . & $1.00(1.00,1.00)$ & . & $1.00(1.00,1.00)$ & . \\
\hline Read and write & $0.17(0.07,0.42)$ & $<0.001$ & $0.71(0.27,1.84)$ & 0.48 & $0.15(0.04,0.53)$ & $<0.001$ & $0.39(0.06,2.54)$ & 0.33 \\
\hline Secondary School & $0.15(0.06,0.38)$ & $<0.001$ & $0.72(0.28,1.85)$ & 0.50 & $0.14(0.04,0.50)$ & $<0.001$ & $0.38(0.06,2.39)$ & 0.30 \\
\hline University & $0.14(0.06,0.34)$ & $<0.001$ & $0.55(0.22,1.39)$ & 0.21 & $0.13(0.04,0.45)$ & $<0.001$ & $0.27(0.04,1.72)$ & 0.16 \\
\hline High studies & $0.11(0.04,0.29)$ & $<0.001$ & $0.59(0.22,1.61)$ & 0.30 & $0.09(0.03,0.33)$ & $<0.001$ & $0.34(0.05,2.29)$ & 0.27 \\
\hline \multicolumn{9}{|l|}{ Occupation } \\
\hline Employed & $1.00(1.00,1.00)$ & . & $1.00(1.00,1.00)$ & . & $1.00(1.00,1.00)$ & . & $1.00(1.00,1.00)$ & . \\
\hline Student, not employed & $0.94(0.29,3.10)$ & 0.92 & $0.30(0.08,1.13)$ & 0.07 & $0.60(0.15,2.30)$ & 0.45 & $0.15(0.03,0.71)$ & 0.02 \\
\hline Housewife, not employed & $2.42(1.82,3.23)$ & $<0.001$ & $2.15(1.42,3.24)$ & $<0.001$ & $12.19(8.03,18.51)$ & $<0.001$ & $3.33(1.51,7.32)$ & $<0.001$ \\
\hline Retired & $2.08(1.67,2.58)$ & $<0.001$ & $1.07(0.77,1.49)$ & 0.70 & $3.80(2.72,5.30)$ & $<0.001$ & $1.25(0.72,2.16)$ & 0.44 \\
\hline Unemployed & $3.86(1.85,8.05)$ & $<0.001$ & $1.00(0.38,2.66)$ & 1.00 & $3.62(1.32,9.92)$ & 0.01 & $0.69(0.21,2.23)$ & 0.54 \\
\hline \multicolumn{9}{|l|}{ Marital status } \\
\hline Never married & $1.00(1.00,1.00)$ & . & $1.00(1.00,1.00)$ & . & $1.00(1.00,1.00)$ & . & $1.00(1.00,1.00)$ & . \\
\hline currently married & $2.79(1.90,4.10)$ & $<0.001$ & $2.24(1.35,3.70)$ & $<0.001$ & $4.11(2.95,5.72)$ & $<0.001$ & $2.78(1.68,4.60)$ & $<0.001$ \\
\hline Divorced & $2.85(1.64,4.94)$ & $<0.001$ & $1.82(0.86,3.86)$ & 0.12 & $9.18(4.93,17.10)$ & $<0.001$ & $2.59(1.05,6.42)$ & 0.04 \\
\hline Widowed & $4.02(2.08,7.77)$ & $<0.001$ & $1.51(0.56,4.08)$ & 0.42 & $17.92(6.17,52.01)$ & $<0.001$ & $3.97(0.59,26.96)$ & 0.16 \\
\hline \multicolumn{9}{|l|}{ Average Income } \\
\hline$\leq 500$ & $1.00(1.00,1.00)$ & . & $1.00(1.00,1.00)$ & . & $1.00(1.00,1.00)$ & . & $1.00(1.00,1.00)$ & . \\
\hline$>500-1500$ & $1.84(1.44,2.36)$ & $<0.001$ & $1.78(1.29,2.45)$ & $<0.001$ & $1.98(1.51,2.59)$ & $<0.001$ & $1.75(1.23,2.50)$ & $<0.001$ \\
\hline$>1500$ & $2.46(1.95,3.09)$ & $<0.001$ & $2.17(1.41,3.33)$ & $<0.001$ & $3.32(2.59,4.25)$ & $<0.001$ & $2.25(1.40,3.61)$ & $<0.001$ \\
\hline \multicolumn{9}{|l|}{ Current smoker } \\
\hline No & $1.00(1.00,1.00)$ & . & $1.00(1.00,1.00)$ & & $1.00(1.00,1.00)$ & . & $1.00(1.00,1.00)$ & . \\
\hline Yes & $0.85(0.69,1.05)$ & 0.13 & $2.54(1.02,6.36)$ & 0.05 & $0.70(0.56,0.88)$ & $<0.001$ & $4.61(1.70,12.49)$ & $<0.001$ \\
\hline \multicolumn{9}{|l|}{ Past smoker } \\
\hline No & $1.00(1.00,1.00)$ & . & $1.00(1.00,1.00)$ & . & $1.00(1.00,1.00)$ & . & $1.00(1.00,1.00)$ & . \\
\hline Yes & $1.21(0.89,1.64)$ & 0.22 & $1.45(1.02,2.04)$ & 0.04 & $0.80(0.58,1.12)$ & 0.20 & $1.43(0.96,2.13)$ & 0.07 \\
\hline \multicolumn{9}{|c|}{ Vigorous-intensity physical activity } \\
\hline No & $1.00(1.00,1.00)$ & . & - & - & $1.00(1.00,1.00)$ & . & - & - \\
\hline Yes & $0.68(0.32,1.45)$ & 0.32 & - & - & $0.76(0.42,1.36)$ & 0.35 & - & - \\
\hline
\end{tabular}


Table 3 Univariate and Multivariable analysis of association of obesity, Central Obesity, and study characteristics (Continued)

\begin{tabular}{|c|c|c|c|c|c|c|c|c|}
\hline \multirow[t]{3}{*}{ Characteristics } & \multicolumn{4}{|l|}{ Obesity } & \multicolumn{4}{|l|}{ Central Obesity } \\
\hline & \multicolumn{2}{|l|}{ Univariate } & \multicolumn{2}{|l|}{ Multivariable $^{a}$} & \multirow{2}{*}{$\begin{array}{l}\text { Univariate } \\
\text { OR }(95 \% \mathrm{Cl})\end{array}$} & \multirow[b]{2}{*}{$p$-value } & \multicolumn{2}{|l|}{ Multivariable $^{\mathrm{b}}$} \\
\hline & OR (95\% CI) & $p$-value & OR $(95 \% \mathrm{Cl})$ & $p$-value & & & OR $(95 \% \mathrm{Cl})$ & $p$-value \\
\hline \multicolumn{9}{|c|}{ Moderate-intensity physical activity } \\
\hline No & $1.00(1.00,1.00)$ & & - & - & $1.00(1.00,1.00)$ & & $1.00(1.00,1.00)$ & \\
\hline Yes & $0.99(0.68,1.43)$ & 0.96 & - & - & $0.64(0.43,0.94)$ & 0.02 & $0.79(0.45,1.38)$ & 0.40 \\
\hline \multicolumn{9}{|c|}{ Elevated blood pressure (ACC/AHA) } \\
\hline No & $1.00(1.00,1.00)$ & & - & - & $1.00(1.00,1.00)$ & . & - & - \\
\hline Yes & $1.29(1.07,1.57)$ & 0.01 & - & - & $1.16(0.94,1.44)$ & 0.18 & - & - \\
\hline \multicolumn{9}{|c|}{ Elevated blood pressure (WHO) } \\
\hline No & $1.00(1.00,1.00)$ & . & $1.00(1.00,1.00)$ & . & $1.00(1.00,1.00)$ & . & $1.00(1.00,1.00)$ & . \\
\hline Yes & $1.49(1.12,1.97)$ & 0.01 & $2.34(1.59,3.44)$ & $<0.001$ & $1.26(0.91,1.76)$ & 0.17 & $2.13(1.27,3.59)$ & $<0.001$ \\
\hline
\end{tabular}

${ }^{a}$ Adjusted for gender, age group, nationality, education, occupation, marital status, average monthly household income, current and past smoking status, and elevated blood pressure (WHO)

${ }^{\text {b} A d j u s t e d ~ f o r ~ g e n d e r, ~ a g e ~ g r o u p, ~ n a t i o n a l i t y, ~ e d u c a t i o n, ~ o c c u p a t i o n, ~ m a r i t a l ~ s t a t u s, ~ a v e r a g e ~ m o n t h l y ~ h o u s e h o l d ~ i n c o m e, ~ c u r r e n t ~ a n d ~ p a s t ~ s m o k i n g ~ s t a t u s, ~}$ moderate-intensity physical activity and elevated blood pressure (WHO)

participants reporting physical activity, had a lower rate of obesity. Programmes to improve physical activity in Kuwait will arguably be integral to reducing obesity. It is important that governments integrate physical activity in the NCD prevention programmes at primary health care services.

Relationship between educational attainment and obesity are known to depend on the economic development of a country. Our findings show an inverse relationship between educational attainment and obesity and central obesity, aligning with the findings of a systematic review on educational attainment and obesity, where an inverse relationship was noted for all studies conducted in higher-income countries like Kuwait [53]. Therefore, educational policies to improve physical activity, healthful diet and reduction in smoking habits should be integral in efforts to reduce the prevalence of overweight/obesity in Kuwait.

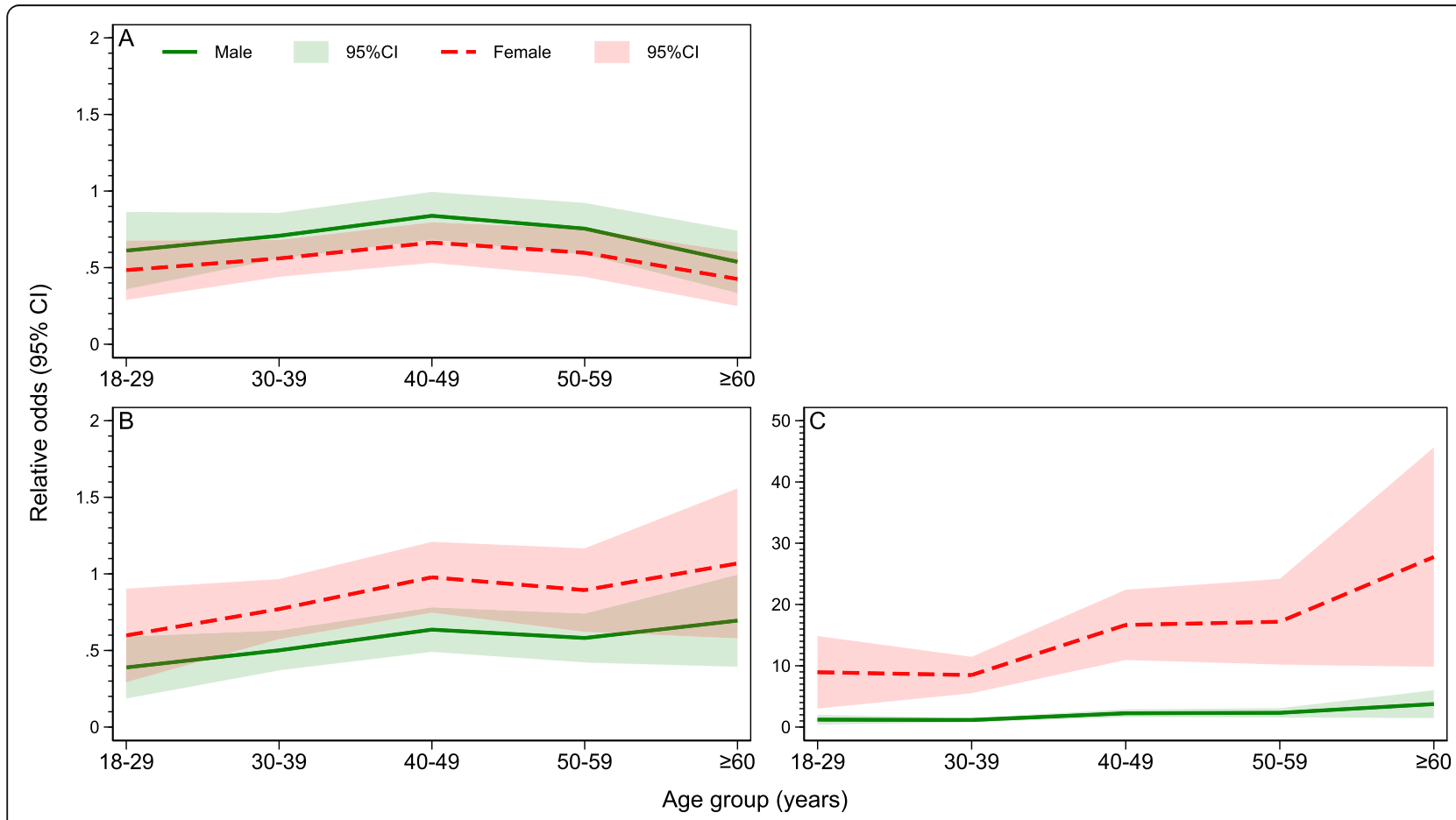

Fig. 4 Relative odds of (a) overweight; b obesity and (c) central obesity (WC) across age groups by gender from fitted multivariable regression 


\section{Strengths and limitations of the study}

Large sample size and nationally representative study population are important strengths of our study. Our evaluation of different anthropometric indices enabled assessment of different types of obesity defined per established criteria. Our comparison of Kuwaiti and non-Kuwaiti resident in Kuwait is unique and has not been previously assessed. A limitation is that some factors were collected via questionnaire, and both recall, and desirability biases are possible.

\section{Conclusion}

This study documents a high prevalence of overweight and obesity in the Kuwaiti population. A high prevalence of overweight/obesity among the young age group 1829 years and unusually high prevalence of physical inactivity underlines the need for early intervention and a life course perspective to reduce and prevent obesity and overweight. Given that education was associated with reduced risk of obesity, integrating mandatory physical education to the school curriculum, and promoting the creation of public parks, recreation spaces to promote physical activities may play a vital role in the early prevention of overweight/obesity in Kuwait. These findings are crucial for public health advocates and policymakers, especially given the high burden of overweight and obesity in the Kuwait population, as they can guide the development of strategies, or action plans to reduce overweight and obesity, and physical inactivity in the population.

\section{Abbreviations}

WHO: World Health Organisation; STEPwise: Approach to Surveillance of noncommunicable diseases (STEPS); BMI: Body mass index; WC: Waist circumference; OW: Overweight; OB: Obesity; GCC: Gulf Cooperation Council; GHO: Global Health Observatory; IDF: International Diabetes Federation; PACl: Public Authority of Civil Information; ACC/AHA: American College of Cardiology/American Heart Association Hypertension; Cl: Confidence interval; KD: Kuwait Dinah; AOR: Adjusted odds ratio

\section{Supplementary Information}

The online version contains supplementary material available at https://doi. org/10.1186/s12889-021-10692-1.

Additional file 1: Supplementary Tables. Table S1. Study

characteristics stratified by age group. Table S2. Study characteristics stratified by nationality.

\section{Acknowledgements}

We are grateful to numerous Dasman Diabetes Institute researchers for their roles in conducting the survey reported on here.

\section{Authors' contributions}

VMO, NC and MD conceived the objective of this study; NC and MD secured funding; SA, VMO processed data; $\mathrm{VMO}$ analysed data and drafted the manuscript; VMO, SA, MA, FHA, FA, NC, and MD reviewed manuscript for important intellectual content. All authors read and approved the final manuscript.

\section{Funding}

We also thank the Dasman Diabetes Institute for providing funding to support data collection of this study. The funders had no role in the study design, data collection, data analysis and interpretation, writing of the manuscript, or the decision to submit the article for publication.

\section{Availability of data and materials}

The raw dataset analysed in this study is not publicly available. It can be provided on reasonable request to Dasman Diabetes Institute through the corresponding author and in line with the provisions of the ethics committee.

\section{Declarations}

\section{Ethics clearance and consent to participate}

This study was conducted by the Dasman Diabetes Institute and approved by an internal institutional review committee (RA2010-004). This review was consistent with the Declaration of Helsinki. All participants signed, in writing, the consent form prior to their enrolment in the study.

\section{Consent for publication}

Not applicable.

\section{Competing interests}

None.

\section{Author details}

${ }^{1}$ Australian Geospatial Health Laboratory, Health Research Institute, University of Canberra, Canberra, Australia. ${ }^{2}$ Geohealth Laboratory, Dasman Diabetes Institute, Kuwait City, Kuwait. ${ }^{3}$ Child Health Division, Menzies School of Health Research, Charles Darwin University, Darwin, Australia. ${ }^{4}$ Biochemistry and Molecular Biology Department, Dasman Diabetes Institute, Kuwait City, Kuwait. ${ }^{5}$ Department of Medicine, St. Vincent's Hospital, The University of Melbourne, Melbourne, Australia.

Received: 28 June 2020 Accepted: 23 March 2021

Published online: 07 April 2021

\section{References}

1. Obesity and overweight [https:/www.who.int/news-room/fact-sheets/deta il/obesity-and-overweight].

2. Naser KA, Gruber A, Thomson GA. The emerging pandemic of obesity and diabetes: are we doing enough to prevent a disaster? Int I Clin Pract. 2006; 60(9):1093-7. https://doi.org/10.1111/j.1742-1241.2006.01003.x.

3. Bhaskaran K, Douglas I, Forbes H, dos-Santos-Silva I, Leon DA, Smeeth L. Body-mass index and risk of 22 specific cancers: a population-based cohort study of 5.24 million UK adults. Lancet. 2014;384(9945):755-65. https://doi. org/10.1016/S0140-6736(14)60892-8.

4. Roberts RE, Deleger S, Strawbridge WJ, Kaplan GA. Prospective association between obesity and depression: evidence from the Alameda County study. Int J Obes Relat Metab Disord. 2003;27(4):514-21. https://doi.org/10.1038/sj. ijo.0802204.

5. Al-Goblan AS, Al-Alfi MA, Khan MZ. Mechanism linking diabetes mellitus and obesity. Diabetes Metab Syndr Obes. 2014;7:587-91.

6. Kim SH, Despres JP, Koh KK. Obesity and cardiovascular disease: friend or foe? Eur Heart J. 2016;37(48):3560-8. https://doi.org/10.1093/eurheartj/ ehv509.

7. Yao TC, Tsai HJ, Chang SW, Chung RH, Hsu JY, Tsai MH, et al. Obesity disproportionately impacts lung volumes, aifflow and exhaled nitric oxide in children. PLoS One. 2017;12(4):e0174691. https://doi.org/10.1371/journal. pone. 0174691 .

8. WHO: Global health observatory data: overweight and obesity. 2016.

9. Weiderpass E, Botteri E, Longenecker JC, Alkandari A, Al-Wotayan R, Al Duwairi $\mathrm{Q}$, et al. The prevalence of overweight and obesity in an adult Kuwaiti population in 2014. Front Endocrinol (Lausanne). 2019;10(449):449. https://doi.org/10.3389/fendo.2019.00449.

10. WHO: Diabetes Country Profiles, Kuwait, 2016. 2016.

11. WHO. Country cooperation strategy for WHO and Kuwait 2012-2016: World Health Organization. Regional Office for the Eastern Mediterranean; 2014. 
12. Alberti KG, Zimmet P, Shaw J, Group IDFETFC. The metabolic syndrome--a new worldwide definition. Lancet. 2005;366(9491):1059-62. https://doi.org/1 0.1016/S0140-6736(05)67402-8.

13. Elkum N, Al-Arouj M, Sharifi M, Behbehani K, Bennakhi A. Cardiovascular disease risk factors in the south Asian population living in Kuwait: a crosssectional study. Diabet Med. 2014;31(5):531-9. https://doi.org/10.1111/ dme.12386

14. Al-Asi T. Overweight and obesity among Kuwait oil company employees: a cross-sectional study. Occup Med (Lond). 2003;53(7):431-5. https://doi.org/1 0.1093/occmed/kgg110.

15. IDF. The IDF Consensus worldwide definition of the metabolic syndrome; 2005. p. 131-9.

16. Al Khalaf MM, Eid MM, Najjar HA, Alhajry KM, Doi SA, Thalib L. Screening for diabetes in Kuwait and evaluation of risk scores. East Mediterr Health J. 2010;16(7):725-31. https://doi.org/10.26719/2010.16.7.725.

17. STEPS Manual for chronic diseases and health promotion [http://www.who. int/chp/steps/manual/en/].

18. Global physical Activity Questionnaire (GPAQ): Analysis guide [http://www who.int/chp/steps/GPAQ/en/].

19. Alberti KG, Zimmet PZ. Definition, diagnosis and classification of diabetes mellitus and its complications. Part 1: diagnosis and classification of diabetes mellitus provisional report of a WHO consultation. Diabet Med. 1998;15(7):539-53. https://doi.org/10.1002/(SICI)1096-9136(199807)15:7<53 9:.AID-DIA668>3.0.CO;2-S.

20. James PT, Leach R, Kalamara E, Shayeghi M. The worldwide obesity epidemic. Obes Res. 2001;9(Suppl 4(S11)):228S-33S.

21. Alberti KG, Eckel RH, Grundy SM, Zimmet PZ, Cleeman Jl, Donato KA, et al. Harmonizing the metabolic syndrome: a joint interim statement of the international diabetes federation task force on epidemiology and prevention; National Heart, Lung, and Blood Institute; American Heart Association; world heart federation; international atherosclerosis society; and International Association for the Study of obesity. Circulation. 2009;120(16): 1640-5.

22. Carey RM, Whelton PK, Committee AAHGW. Prevention, detection, evaluation, and Management of High Blood Pressure in adults: synopsis of the 2017 American College of Cardiology/American Heart Association hypertension guideline. Ann Intern Med. 2018;168(5):351-8. https://doi.org/1 0.7326/M17-3203.

23. Ismail M, Al Mutawa N, Al Musallam M. Prevalence of obesity in Qataris attending primary health care centers in Doha, 2008. Qatar Med J. 2011; 2011(2):8. https://doi.org/10.5339/qmj.2011.2.8.

24. Al-Kadi A, Malik AM, Mansour AE. Rising incidence of obesity in Saudi residents. A threatening challenge for the surgeons. Int J Health Sci (Qassim). 2018;12(1):45-9.

25. Al-Qahtani AM. Prevalence and predictors of obesity and overweight among adults visiting primary care settings in the southwestern region, Saudi Arabia. Biomed Res Int. 2019;2019:8073057. https://doi.org/10.1155/2 019/8073057.

26. Qawas A, Razzak H, El-Metwally A, Harbi A, Al-Shujairi A. The prevalence and risk factors of obesity in the United Arab Emirates. Saudi J Obes. 2017;5(2):57-65.

27. AL-Nooh AA, Almaji AAA, Wood D. The prevalence of cardiovascular disease risk factors among employees in the Kingdom of Bahrain between October 2010 and March 2011: a cross-sectional study from a workplace health campaign. Cardiol Res Pract. 2014;2014:832421. https://doi.org/10.1155/2 014/832421.

28. Musaiger AO. The state of food and nutrition in the Arabian gulf countries World Rev Nutr Diet. 1987;54:105-73. https://doi.org/10.1159/000415304.

29. Joseph S, Naǧmābādī A. Encyclopedia of Women \& Islamic Cultures: family, body, sexuality and health, vol. 3: Brill; 2003.

30. Al-Awadi F, Amine E, Z G. Food Consumption and Dietary Habits in Kuwait. Kuwait: Food and Nutrition Administration, Ministry of Health Kuwait; 1997.

31. Chapman IM. Obesity in old age. Obes Metab. 2008;36, edn.: Karger Publishers:97-106.

32. Hajek A, Lehnert T, Ernst A, Lange C, Wiese B, Prokein J, et al. Prevalence and determinants of overweight and obesity in old age in Germany. BMC Geriatr. 2015;15(1):83. https://doi.org/10.1186/s12877-015-0081-5.

33. Zamboni M, Mazzali G. Obesity in the elderly: an emerging health issue. Int J Obes. 2012;36(9):1151-2. https://doi.org/10.1038/ijo.2012.120.

34. Jura M, Kozak LP. Obesity and related consequences to ageing. Age (Dordr). 2016;38(1):23. https://doi.org/10.1007/s11357-016-9884-3.
35. Ogden CL. Statistics NCfH: obesity and socioeconomic status in adults: United States, 2005-2008: US Department of Health and Human Services, Centers for Disease Control and Prevention: National Center for Health Statistics; 2010.

36. Wang $Y$, Lim $H$. The global childhood obesity epidemic and the association between socio-economic status and childhood obesity. Int Rev Psychiatry. 2012;24(3):176-88. https://doi.org/10.3109/09540261.2012.688195.

37. Jones-Smith JC, Gordon-Larsen P, Siddiqi A, Popkin BM. Cross-National Comparisons of time trends in overweight inequality by socioeconomic status among women using repeated cross-sectional surveys from 37 developing countries, 1989-2007. Am J Epidemiol. 2011;173(6):667-75. https://doi.org/10.1093/aje/kwq428.

38. Cai L, He J, Song Y, Zhao K, Cui W. Association of obesity with socioeconomic factors and obesity-related chronic diseases in rural Southwest China. Public Health. 2013;127(3):247-51. https://doi.org/10.1016/j.puhe.2 012.12.027.

39. Oguoma VM, Nwose EU, Skinner TC, Digban KA, Onyia IC, Richards RS. Prevalence of cardiovascular disease risk factors among a Nigerian adult population: relationship with income level and accessibility to CVD risks screening. BMC Public Health. 2015;15(1):397. https://doi.org/10.1186/s12 889-015-1709-2.

40. Akil L, Ahmad HA. Effects of socioeconomic factors on obesity rates in four southern states and Colorado. Ethn Dis. 2011;21(1):58-62.

41. Newton S, Braithwaite D, Akinyemiju TF. Socio-economic status over the life course and obesity: systematic review and meta-analysis. PLoS One. 2017; 12(5):e0177151. https://doi.org/10.1371/journal.pone.0177151.

42. Han TS, Lee DM, Lean ME, Finn JD, O'Neill TW, Bartfai G, et al. Associations of obesity with socioeconomic and lifestyle factors in middle-aged and elderly men: European male aging study (EMAS). Eur J Endocrinol. 2015; 172(1):59-67. https://doi.org/10.1530/EJE-14-0739.

43. Hoebel J, Kuntz B, Kroll LE, Schienkiewitz A, Finger JD, Lange C, et al. Socioeconomic inequalities in the rise of adult obesity: a time-trend analysis of National Examination Data from Germany, 1990-2011. Obes Facts. 2019; 12(3):344-56. https://doi.org/10.1159/000499718.

44. Monteiro CA, Moura EC, Conde WL, Popkin BM. Socioeconomic status and obesity in adult populations of developing countries: a review. Bull World Health Organ. 2004:82(12):940-6 DOI: /S0042-96862004001200011.

45. Hou X, Jia W, Bao Y, Lu H, Jiang S, Zuo Y, et al. Risk factors for overweight and obesity, and changes in body mass index of Chinese adults in Shanghai. BMC Public Health. 2008;8(1):389. https://doi.org/10.1186/1471-24 58-8-389.

46. Templin T, Cravo Oliveira Hashiguchi T, Thomson B, Dieleman J, Bendavid E. the overweight and obesity transition from the wealthy to the poor in lowand middle-income countries: a survey of household data from 103 countries. PLoS Med. 2019;16(11):e1002968. https://doi.org/10.1371/journal. pmed. 1002968

47. Sulaiman N, Elbadawi S, Hussein A, Abusnana S, Madani A, Mairghani M, et al. Prevalence of overweight and obesity in United Arab Emirates expatriates: the UAE National Diabetes and lifestyle study. Diabetol Metab Syndr. 2017;9(1):88. https://doi.org/10.1186/s13098-017-0287-0.

48. Badr HE, Shah NM, Shah MA. Obesity among Kuwaitis aged 50 years or older: prevalence, correlates, and comorbidities. Gerontologist. 2013;53(4): 555-66. https://doi.org/10.1093/geront/gns108.

49. Behbehani NN, Hamadeh RR, Macklai NS. Knowledge of and attitudes towards tobacco control among smoking and non-smoking physicians in 2 gulf Arab states. Saudi Med J. 2004;25(5):585-91.

50. Hamadeh RR. Smoking in the Gulf cooperation council (GCC) countries. Bahrain Med Bull. 1998;20(3):91-4.

51. Dare S, Mackay DF, Pell JP. Relationship between smoking and obesity: a cross-sectional study of 499,504 middle-aged adults in the UK general population. PLoS One. 2015;10(4):e0123579. https://doi.org/10.1371/journal. pone.0123579.

52. WHO. In: Organisation WH, editor. Global Health Observatory data: Prevalence of insufficient physical activity; 2016.

53. Cohen AK, Rai M, Rehkopf DH, Abrams B. Educational attainment and obesity: a systematic review. Obes Rev. 2013;14(12):989-1005. https://doi. org/10.1111/obr.12062.

\section{Publisher's Note}

Springer Nature remains neutral with regard to jurisdictional claims in published maps and institutional affiliations. 